even those taking a fringe approach should be given their due. But as Eternity Soup makes clear, it is important to know when the line is being crossed. By openly engaging in uncontrolled non-scientific experiments on patients, with the rationale that there is no time to wait for science to prove them right, the anti-ageing industry has stepped beyond it.
S. Jay Olshansky is a professor in the School of Public Health at the University of Illinois at Chicago, Illinois 60612, USA, and a research associate at the Center on Aging at the University of Chicago, Illinois 60637, USA.

e-mail: sjayo@uic.edu

See Editorial, page 465.

\title{
Learning from history's trials
}

\author{
Natural Experiments of History \\ Edited by Jared Diamond and \\ James A. Robinson \\ Belknap Press: 2010. 288 pp. $\$ 29.95$
}

Natural Experiments of History is a short book packed with huge ideas. Its collected essays advocate how controlled experiments can be applied to the messy realities of human history, politics, culture, economics and the environment. It demonstrates productive interdisciplinary collaborations but also reveals gulfs between different cultures of academia.

The editors, geographer Jared Diamond and political economist James Robinson, have ensured that the volume of essays is cohesive and tightly argued. Many of the authors choose to start arguments, not finish them, by venturing important and controversial claims, together with clear explanations of their comparative regional studies.

The idea of a natural experiment is simple: find two or more cases that share some significant attributes but not others, and probe the similarities and differences systematically. Using studies of islands to make two opposing arguments, Diamond's essay may surprise critics who dismiss him as a geographic determinist. Comparing Haiti and the Dominican Republic - two nations that split one island - he argues that their different histories of colonization and rule have trumped environmental factors in determining how each side has developed. Today, the Dominican Republic has a functioning democracy, an average per capita income that is six times that of its neighbour, and 28\% intact forest compared with just $1 \%$ in Haiti. Attributing that success to "cultural, economic, and political differences" is a fair generalization, but in history, the devil is always in the details.

The second case study in Diamond's essay is more quantitative. Across 69 Pacific islands, he analyses nine environmental variables - including the geological age of soils, deforestation, rainfall, temperature and wind-borne deposition of dust and ash — and four agricultural practices, namely wet and dry cultivation of root crops, and arboriculture of breadfruit and nuts. He concludes that Easter Island was deforested because its inhabitants "had the bad luck to find themselves living on one of the Pacific's most environmentally fragile islands". This may confuse those who have read Diamond's arguments that it was Easter Islanders' failure to adapt culturally to their limited environment that caused their society to collapse. Was it their own fault, bad luck, or

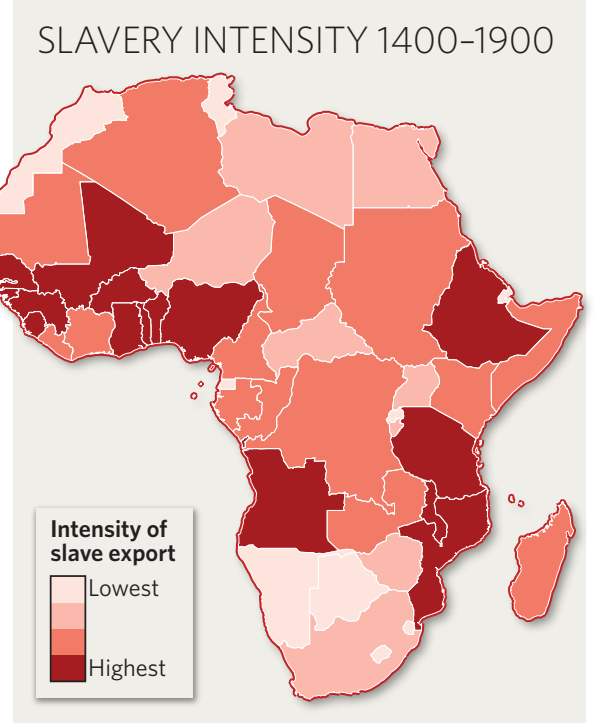

The historical intensity of slave export from Africa correlates with poverty there today.

both? Diamond seems to want to have it both ways.

History trumps geography in another provocative essay, 'Shackled to the past', by economist Nathan Nunn. He examines the relationship between the historical trade in slaves from different parts of Africa, and modern per capita income and gross domestic product in those areas. His statistical analysis reveals that the more slaves that were taken from an African country, the poorer it is today (see graphic). Nunn estimates that, without the slave trade, per capita incomes in Africa today would be between $45 \%$ and $180 \%$ higher than the US\$1,834 average annual income in 2000. It is a persuasive argument for targeted reparations for the slave trade.

This daring reach for revealing patterns is both a strength and a weakness of Natural Experiments of History. Devilish details are necessarily left behind. Historian James Belich's essay, for example, is condensed from his book Replenishing the Earth (Oxford University Press, 2009), a lengthy, nuanced history of Anglo settler societies. In this short version, Belich compares the remarkably similar patterns of explosive population growth and cycles of economic boom and bust that were experienced by disparate settler societies in the western United States, western Canada, Argentina, Australia, New Zealand, Siberia and South Africa in the nineteenth and early twentieth centuries. He argues that each of these societies went through a three-step rhythm: an initial boom fuelled by settlement itself, followed by a bust when these economies proved internally unsustainable, and then a phase of 'export rescue', in which settler colonies supplied commodities to an increasingly networked global economy.

Belich's quest to identify shared 'initial conditions' to explain this world-spanning phenomenon is audacious. He identifies important historical, economic, technological and cultural patterns: the 'peace bonus' of 1815 at the end of the Napoleonic and British-American conflicts, the growing mass transfer of international trade owing to fast clipper ships and a marked shift from a negative to a positive view of emigration, aided by a blossoming print culture. But Belich himself admits that the evidence is mixed when one looks closely at the particulars in each place.

All of the essays in Natural Experiments of History will trigger debate. Diamond and his co-authors will be ready: they are on a mission to import a scientific approach to history to tease out causal factors and build predictive theories. Social scientists also gravitate to this approach. But many historians will argue that there is nothing natural about these experiments, and that they are not experiments anyway because history cannot be replicated. Ultimately, most historians fall back on contingency; stuff happens and the details make all the difference. The power of comparison, pattern, theory and prediction, however, will not be so easily dismissed.

Jon Christensen is executive director of the Bill Lane Center for the American West at Stanford University, Stanford, California 94305, USA. e-mail: jonchristensen@stanford.edu 